\title{
Corrigendum
}

\section{Corrigendum to "Hardware Accelerators Targeting a Novel Group Based Packet Classification Algorithm"}

\author{
O. Ahmed $(D)$, S. Areibi $(D$, and G. Grewal \\ School of Engineering and Computer Science, University of Guelph, Guelph, ON, Canada N1G 2W1 \\ Correspondence should be addressed to S. Areibi; sareibi@uoguelph.ca
}

Received 26 February 2018; Accepted 27 February 2018; Published 1 April 2018

Copyright (c) 2018 O. Ahmed et al. This is an open access article distributed under the Creative Commons Attribution License, which permits unrestricted use, distribution, and reproduction in any medium, provided the original work is properly cited.

In the article titled "Hardware Accelerators Targeting a Novel Group Based Packet Classification Algorithm" [1], the authors would like to acknowledge that this article builds on their previous conference publications mentioned below and that they reused some of the text from these conference papers. The authors would also like to acknowledge the minor reuse from and lack of citation to the Taylor and Turner thesis (4).

(1) O. Ahmed and S. Areibi, "GBSA: A group based search algorithm for packet classification," 2011 7th International Wireless Communications and Mobile Computing Conference, Istanbul, 2011, pp. 1789-1794. doi: 10.1109/IWCMC.2011.5982806, which is cited as reference [26].

(2) O. Ahmed, S. Areibi, and D. Fayek, "PCIU: an efficient packet classification algorithm with an incremental update capability," in Proceedings of the International Symposium on Performance Evaluation of Computer and Telecommunication Systems (SPECTS '10), pp. 81-88, Ottawa, Canada, July 2010, which is cited as reference [11].

(3) O. Ahmed, K. Chattha, and S. Areibi, "A hardware/software co-design architecture for packet classification," in Proceedings of the IEEE International Conference on Microelectronics, pp. 96-99, Cairo, Egypt, December 2010, which is cited as reference [3].

(4) D. E. Taylor and J. S. Turner: "Models, Algorithms, and Architectures for Scalable Packet Classification" Ph.D. thesis, WUCSE-2004-40 http://web.archive.org/web/20060912123051/http://www.cse.seas .wustl.edu/Research/FileDownload.asp?350, which is not cited.

\section{References}

[1] O. Ahmed, S. Areibi, and G. Grewal, "Hardware accelerators targeting a novel group based packet classification algorithm," International Journal of Reconfigurable Computing, vol. 2013, Article ID 681894, 2013. 


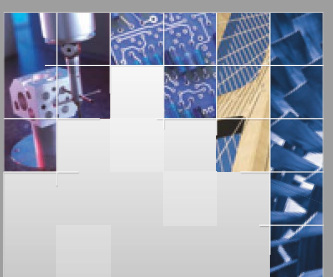

\section{Enfincering}
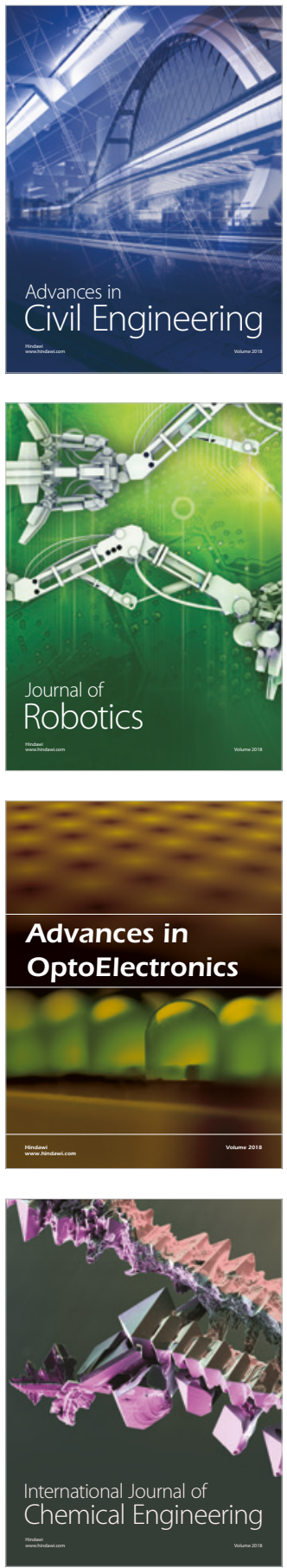

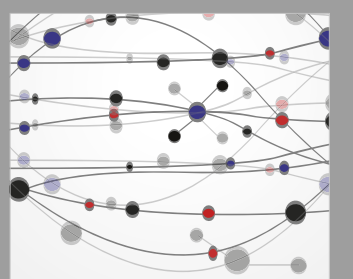

\section{Rotating \\ Machinery}

The Scientific World Journal

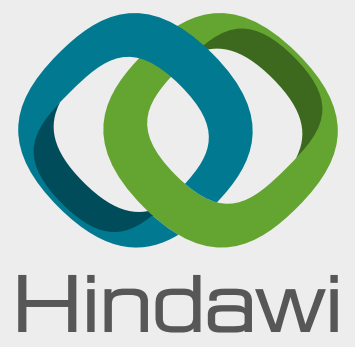

Submit your manuscripts at

www.hindawi.com
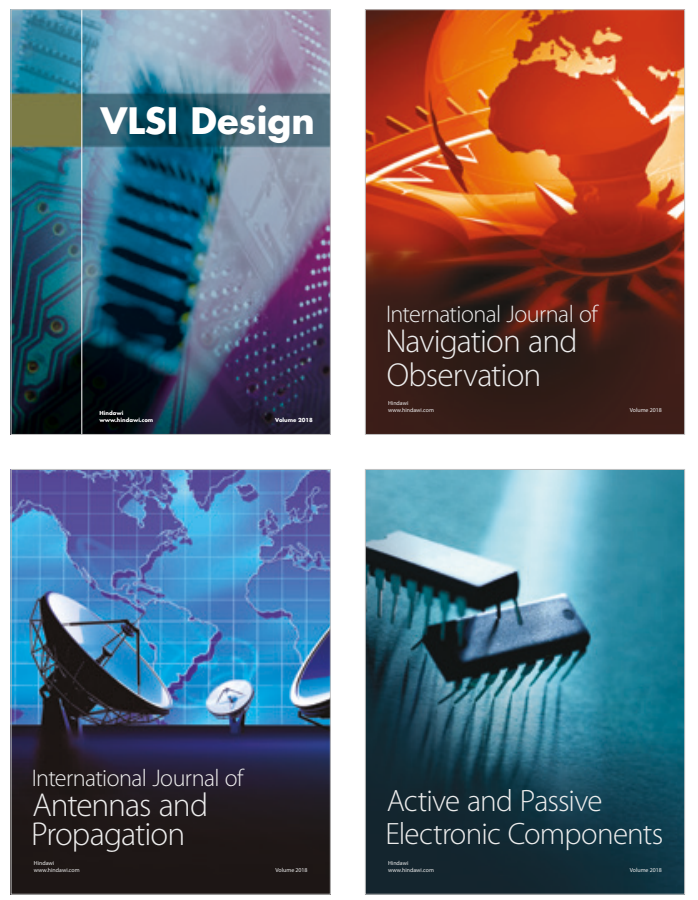
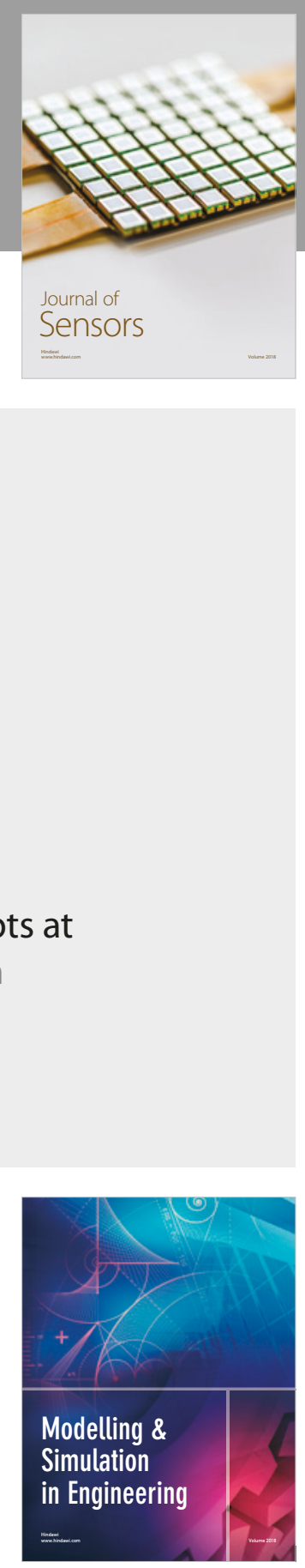

\section{Advances \\ Multimedia}
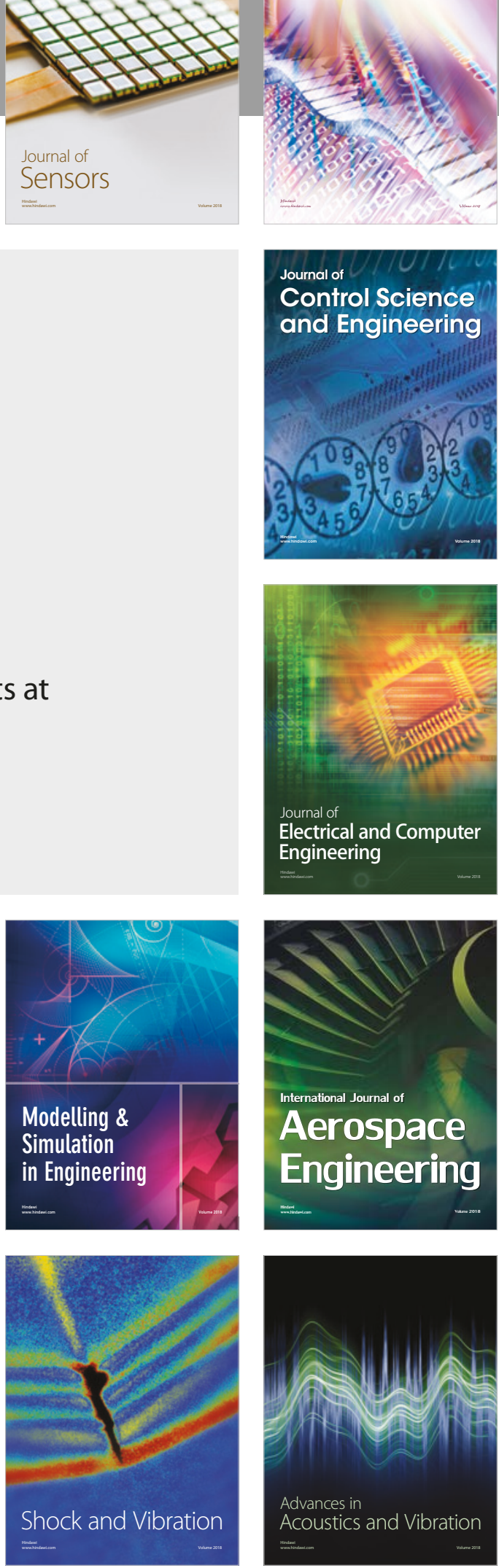